$\xi \mathrm{p}=$

\title{
Evaluation of bronchial asthma educational package on asthma self-management among school age children based on Orem's self-care model in Zagazig city
}

\author{
Fathia Ahmed Mersal ${ }^{1}$, Samah El-Awady ${ }^{2}$ \\ ${ }^{1}$ Community Health Nursing Faculty of Nursing, Ain Shams University \\ ${ }_{2}^{2}$ Pediatric Nursing Department Faculty of Nursing, Zagazig University \\ *Corresponding author E-mail: khtottakh@gmail.com
}

\begin{abstract}
Background: Asthma is the widespread health problem and most common chronic disease among children. Developing self-care skills related to children with asthma forms a basis for nursing care. Orem's self-care model is one of the most comprehensive self-care theories that provide a good clinical guide for planning and implementing the principles of good self-care.

The Aim of this study: was to determine the effect of asthma educational package based on Orem's self-care model on the development of self-care activities of children with asthma.

Subjects and Methods: a quasi-experimental study conducted on a purposive sample of 106 children with bronchial asthma in pediatric outpatient clinic at Zagazig University hospital. The research tools used in this study were demographic characteristics of studied children. Asthma triggers inventory, asthma knowledge questionnaire, asthma self-management questionnaire, asthma Self-Efficacy regarding self-management of asthma, medication adherence, and inhaler technique observation checklist and health instruction guidelines.

Results: the results showed that after the training intervention self-efficacy, asthma management, adherence of asthmatic children to medications were significantly increased $(\mathrm{p}>000)$. The study findings concluded that the asthma education program improved all aspects of self-efficacy and activities of asthma management after program implementation.

Conclusion: the educational program based on Orem's self-care model successfully improves the performance of inhaler use. The study indicates that self-care activities were efficient among children with asthma after implementation of program.

Recommendations: it suggested to conduct Orem's self-care model for children with bronchial asthma and to replicate the study in many settings to support its effectiveness.
\end{abstract}

Keywords: Evaluation; Asthma Educational Package; Asthma Management; Orem's Self-Care Model; School Children.

\section{Introduction}

Asthma is the widespread health problem and most common chronic disease among children and adolescents, with a worldwide prevalence of $14 \%$ ( Coelho et al, 2017). In Egypt, the prevalence of asthma in children (2-12 years) is nearly $8.2 \%$. In El-Menoufiya governorate the prevalence of childhood bronchial asthma among primary school children is $6.5 \%$, which illustrates a significant increase over the last 20 years when compared with a previous prevalence rate of $2.2 \%$ in a similar study conducted more than 20 years ago. This reflects a significant increase in the magnitude of the problem of bronchial asthma in our community and the need for effective prevention and management programs (El-Mashad et al, 2016).

Bronchial asthma is a chronic inflammatory disease of the airways associated with widespread narrowing of the airways and is characterized by symptoms of coughing, wheezing and asthma attacks (Nejad et al, 2017).Uncontrolled Bronchial asthma during childhood leads to continuous symptoms, and serious limitations in physical activities which, can lead to development of chronic obstructive pulmonary disease during the later years of life. Therefore appropriate control of the illness is a major importance during childhood to avoid the morbidity due to asthma (Gajanan et al, 2016).

Patient education has been identified as a key intervention component to improve asthma outcomes in all fields of nursing for decades. Education aims at provision of asthma information that does not only improves patients' knowledge related to their health but also, helps them to take a more active role in the self-care management of their own condition and self-monitoring. Patient education in asthma self-management has emerged as a therapeutic intervention to help patients to manage and recognize asthma, and hopefully to become active, self-efficacious participants in their asthma care (Al-Atawi, 2017). Additionally Asthma selfmanagement education programs for children and adolescents leads to significant improvement in lung function, controlling the disease, reduce missed school days, reduces emergency department visits and hospital admissions (Elliott et al 2014).

Compliance with therapeutic regimens in bronchial asthma, particularly in children, is low. Education is the cornerstone for asthma management, and has been recommended by national and international guidelines. Additionally, it has been cited as an essential component of any asthma management strategy, by improving asthma knowledge and changing behavior. Recently there is little awareness about asthma in most of the developing countries (Coelho et al 2017, and Gajanan et al, 2016). Managing 
asthma is a challenging task as it requires sustained performance of numerous behaviors from patients, their relatives, and the health care providers involved in their care (Janssens\& Ritz, 2013). Management of asthma and allergies consists of pharmacological management, combined with avoidance of triggers that cause symptom exacerbations (Dima et al, 2016).

Considering that, in the therapeutic management of chronic diseases, training programs are very significant for patients and their caregivers, and the selection of a health education model is the first stage in the planning process. Therefore, in this study, the Orem's self-care model was used as a strong theoretical model whereas, Orem's self-care model is one of the most comprehensive self-care theories that provide a good clinical guide for planning and implementing the principles of good self-care. Orem believes that human beings can take care of themselves and whenever this capability is distorted in a person, nurses can help persons to recover this capability by providing direct care, and compensatory educational advocacy. According to Orem, the nurse's role has been introduced as a facilitator and agent of change (Borji et al, 2017).

Self-care is efficient, learned, informed and objective activities and behaviors of individuals that are done in particular situations of life, by the person himself or his caregivers. The purpose of self-care is to arrange the effective factors on growth and patient's performance in relation to life, health, and well-being. Self-care behavior is affected by the total skills and knowledge that a person has and utilizes for his practical efforts. Self-care is considered as an essential and valuable principle because it confirms the active role of persons in their own healthcare, not the passive. Many health organizations and healthcare professionals consider promoting self-care as a strategy to reduce the high costs of medical services (Hemati et al, 2015). Self-care thus consists of a variety of care activities deliberately engaged in to promote physical, mental and emotional health in order to maintain life and prevent disease (Rabie and Klopper, 2015).

Based on this model, structured asthma education tailored to the patient needs on self-care management promote adherence with inhaler devices and self-monitoring. If a patient understand the risks of non-compliance and benefits of compliance and believes the treatment is safe, it will improve their motivation and confidence to enhance their self-management practices. Hence providing right information on self-monitoring and adherence to medications, appropriate dietary measures and breathing exercises improves the disease control and reduces suffering due to frequency of acute attacks (Manchana and Mahal, 2014). Nurses could have a great contribution to promoting self-care capability in patients thanks to playing roles in training, coaching and guidance (Hemati et al, 2015). Nurses are often at the frontline in providing the care, education, and support that enables persons with health care deviations to recognize a change in health status and to find suitable assistance (Kaur et al, 2009).

\section{Significance of the problem}

Asthma is one of the most popular causes for medical assistance when, it comes to primary care, as more than five million schoolage children have physician-diagnosed asthma. In addition, to being a main reason of hospitalization in children less than 15 years of age. Asthma also, accounts for 13 million lost days of school annually (Urrutia-Pereira et al, 2017).Despite several decades of advancement in the control and management of asthma. It remains a common worldwide health and socio-economic problem. Statistically, an estimated 334 million are currently asthmatic worldwide (Al-Atawi, 2017). Additionally, in Cairo, Egypt 2006, the prevalence of asthma was $9.4 \%$ (Georgy et al, 2006). This rate was different from recently estimated in the Nile Delta region of Egypt2010 of 7.7\% (Zedan et al, 2009).

For chronic diseases, self-care includes inspection and control of symptoms, adherence to diet, preservation of a healthy lifestyle and management of disease contribution to daily activities, emo- tions and social relationships. Significant principle of self-care is patient's participation and assumption of self-care responsibility. Nurses could have a major contribution to promoting self-care ability in patients thanks to playing roles in training, coaching and guidance. The self-care ability was introduced by Orem as a constituent of nursing theory, including individual ability of self-care (Hemati et al, 2015).

Among self-care-based theories is the Orem model. This theory considers two factors of demand for self-care. In accordance to Altay and Çavuşoğlu (2013) studied the effect of the Orem model on self-care in the adolescents with asthma. They taught the proper use of medication, exercise techniques, use of action plans, careful diet, and protection against stimulants that resulted significant difference in the intervention group, compared with preintervention. In addition, Tang arayasap et al. Revealed that the control of self-care behaviors in patients with asthma improves following the Orem model intervention (Hemati et al, 2015).

\subsection{Aim of the study}

This study was performed to determine the effect of asthma educational package based on Orem's self-care model on the development of self-care activities of children with asthma through:

- Assess knowledge of children regarding bronchial asthma.

- Evaluate self-efficacy of self-care activities among children regarding bronchial asthma.

- Determine self-care activities among children regarding bronchial asthma.

- Assess adherence to medications regarding bronchial asthma among children.

- Evaluate performance of inhaler use regarding bronchial asthma among children.

\subsection{Hypothesis of the study}

In order to accomplish the research aim of this study the following hypotheses was suggested: structured bronchial asthma educational package performed according to Orem's self-care model would improve children's self-care skills in illness management.

\section{Subjects and methods}

\subsection{Research design}

The present study is an interventional quasi-experimental study design. Study group only pre, post and follow up test.

\subsection{Setting}

The present study was conducted at Pediatric Outpatient Clinic at Zagazig University Hospital (Outpatient Clinics Hospital)

\subsection{Subjects}

The sample size was calculated taking in consideration a significance level of $95 \%$, power $80 \%$ and effect size $25 \%$.Resulting in 100 children to be selected where 106 children participated in our study. Purposive sample Research samples in this study were 106 children with bronchial asthma who, were referred to Pediatric Outpatient Clinic at Zagazig University Hospital and were selected by a purposive sampling method if the inclusion criteria were fulfilled.

Inclusion criteria: children (male and female) with asthma between the ages of 10 and 18 years who, were referred to the hospital with a definitive diagnosis by the doctor. Only children diagnosed with asthma at least 1 year ago, who had no chronic illness other than asthma, and who agreed, with parent approval, to participate in the study and who had ability to read and write. 


\subsection{Tools of data collection}

The following 3 tools were used to collect data related to this study; The First Tool; was structured interview questionnaire. It was written in a simple Arabic language after translation using back translation technique and comprises 6 parts. The first part was concerned with demographic characteristics of studied children such as; age, gender, period of disease, school absenteeism, and father and mother education. The second part includes assessment of asthma triggers Asthma Triggers - Asthma triggers was measured by using the Asthma Trigger Inventory (ATI) (Ritz et al., 2006). The ATI consists of 31-item self-report inventory. The ATI has adequate internal consistency reliability with Cronbach' $\mathrm{s}$ alpha ranging from 0.81 to 0.94 , it was translated into Arabic language using back translation technique.

The third part: Asthma Knowledge Questionnaire (AKQ); It was adopted from (Alreshidi, 2015) Arabic version who adapted the English version from (AlMotlaq \& Sellick, 2011). The instrument consists of 24 questions ( 23 true/false items and one open-ended question) including: general data about asthma, triggers, symptoms, and asthma treatment and management. The domains of the AKQ are well constructed, with evidence of construct and discriminate validity, high internal consistency of items and testretest reliability. The total score of knowledge was 27 degree, the first score was given for each correct answer and zero for incorrect answer. For each area of knowledge, the scores of the questions were summed-up and the total score divided by the number of the items. These scores were converted into a percent score. The total children' knowledge was considered satisfactory if the percent score was $60 \%$ or more and unsatisfactory if less than $60 \%$.

The fourth part: Asthma Self-management which adopted from (Mancuso et al., 2010). It was translated into Arabic language using back translation technique.

The behavior of asthma self-management is defined as strategies to manage asthma daily as well as during acute episodes and to allow children to perform activities of daily living and was measured by the Asthma Self-Management Questionnaire (ASMQ) (Mancuso et al., 2010). The ASMQ is a 16-item, multiple choice questionnaires that measures self-management strategies for asthma. There is only one correct response and total scores range from 0 to 16 . The ASMQ measures management using preventive strategies, inhaler use, differences between maintenance and rescue medications, and use of peak flow meters. A score of 0 to 100 is calculated, with higher scores indicating higher knowledge of asthma self-management. The score was obtained by this formula (raw score/16) x 100. Construct validity was established and adequate internal consistency reliability has been demonstrated with a Cronbach $\alpha$ of 0.71 (Mancuso et al., 2010).

The fifth part: Asthma Self-Efficacy of Self-Management of Asthma Survey which contained 22 items describing how confident one was in performing an asthma self-management behavior. It was adopted from (McCorkle, 2005) who designed it for children from 10 to 18 years old. It was translated into Arabic language using back translation technique. The AMES used a fourresponse category Likert scale with one being "not at all confident" and four being "completely confident". Completely confident on the scale, a rating of four indicated that the student felt completely confident in the specific asthma self-management knowledge or skill. The mean score for the AMES was 58.0 and the standard deviation was 12.0. In terms of internal consistency, the AMES has a Cronbach Alpha of 0.84, which represents the reliability with which the AMES measures asthma self-efficacy of self-management of asthma.

The six part: Medication Adherence - Medication adherence was measured by the Morisky adherence scale which is an 8-item questionnaire, and which is a valid measure of self-reported adherence. It has been used to measure medication adherence in asthma. It was translated into Arabic language using back translation technique. Total scores range from 0 to 4 , where 0 indicates high adherence, and 4 indicates non adherence. Patients responding with a score of " 0 " are classified as "high adherent"; patients having scores from 1 to 2 are classified as "medium adherent"; and patients having scores greater than 2 (3-8) are classified as "low adherent". This instrument has adequate internal consistency reliability with a Cronbach alpha coefficient of 0.80 and concurrent and predictive validity has been established (Morisky, 2008).

Second Tool: concerned with assessment of patient inhaler technique by using observation checklist; adopted from (Magwentshu, 2010). Enrolled children were assessed for inhalation technique at their routine medical (pre-training) visits by a qualified nurse without prior notification. This assessment was performed in outpatient room. The use of each inhaler device was assessed in a practical manner by asking children to demonstrate their inhalation technique using their prescribed devices containing placebo medications. They were asked to say each step as they were performing it, so that all of the steps could be clearly observed. It consists of 11 items to assess child inhaler use. If the performance was correct the participant scores one, and if incorrect or not done he or she scores zero. Child's performance considered adequate if the total score of checklist was $75 \%$ or more.

Third Tool: Health Instructions guidelines

Health instructions guidelines were developed to educate school age children with bronchial asthma and aimed to improve school age children' knowledge and practices regarding selfmanagement, self-efficacy and prevention

The content of the health instructions selected and the health instructions were planned and developed according to careful study of bronchial asthma' educational needs revealed from the assessment phase, and reviewing the relevant literature. Teaching methods were selected to suit teaching small groups' learners in the form of lectures, group discussion, demonstration, and redemonstration. Teaching materials were prepared as booklet, brochures and colored posters that covered theoretical and practical information. The health instructions have been implemented through five sessions. The length of each session ranged about 3545 minutes. Asthmatic children divided into small groups; each group consisted of five to seven participants.

Evaluation of the health instructions success based on the improvement of the asthmatic school age children' knowledge and practices, this evaluation was initiated before the health instructions, immediately after the health instructions and then after 2 months.

\subsection{Validity and reliability}

Testing validity of the study tools was done by a jury of 5experts from different academic categories (professors of pediatric Nursing and professors of Community Health Nursing) at the faculty of nursing. Testing reliability of the proposed tools was done statistically by Cronbach's alpha test.

\subsection{Administrative and ethical considerations}

An official permission for collection of data was obtained by submission of an official letter issued from the director of the faculty of nursing at Zagazig University to the director of Out-Patient Clinics Hospital "Pediatric Outpatient Clinic" at Zagazig University Hospital. Oral consent was obtained from the studied asthmatic children after clarification of the aim and process of the study, as well as assurance of maintaining anonymity and confidentiality of subjects' data, and emphasis on the patient's right to withdraw from the study at any phase.

\subsection{Pilot study}

A pilot study was conducted on 5 asthmatic children to test the clarity of questions and to estimate the time required for using the tools. No modification was done to the tools; accordingly asthmatic children' who, shared in the pilot study were included in the study sample. 


\subsection{Field work}

This study conducted through four consecutive phases: assessment, planning, implementation and evaluation. Data collection was done pre and post guidelines implementation.

I) Assessment phase:

The tools of data collection were developed and translated to Arabic language by the researchers after thorough detailed review of literature. The researchers started with a pilot test, and then validated the tool through the opinions of experts in nursing. Then, the researchers attended the Pediatric Outpatient Clinic four days/week for data collection to identify their knowledge and skills regarding bronchial asthma. Each child was individually interviewed to complete tool I and tool II (pretest/assessment phase).

II) Planning phase

Based on the assessment phase, the program content and media (in the form of the program and implementation of health instructions) were prepared. The health instructions (tool III) were developed on the basis of the results of the assessment phase and reviewing the relevant literature in Arabic language.

\section{III) Implementation phase}

Implementation of the program conducted with the asthmatic children after explanation of the purpose of the study and their acceptance of participation. The health instructions guidelines were implemented through five sessions, and were given in small groups; each group consisted of five to seven participants. Data were collected and program was implemented over a period of 7 months, starting from January 2015 to April 2016. Individual sessions, group discussions, demonstrations and re-demonstrations used as teaching methods. Audio-visual aids as video clips, roleplays, brochures and introduction of a booklet were used to facilitate the process of educational program to serve the purposes for which it designed.

IV) Evaluation phase

The evaluation phase emphasized on estimating the effect of the educational guideline on children' knowledge and practice regarding bronchial asthma management, after implementation of the health instructions guidelines, the studied asthmatic children were individually re-interviewed to assess their knowledge and practices (posttest) using tool I and tool II. Adolescents' knowledge and practices were reassessed again after two months of health instructions implementation (follow up) using the same tools.

\subsection{Statistical design}

Data entry, validation and analysis were done with the statistical package for social science version 17.0. Data were presented in tables and charts using actual numbers and percentages. Appropriate statistical methods were applied (percentage, chi-square $\left(\chi^{2}\right)$, Repeated measure ANOVA). Regarding $\mathrm{p}$ value, it was considered that: non-significant (NS) if $p>.05$, Significant $(\mathrm{S})$ if $\mathrm{p}<.05$, Highly Significant (HS) if $\mathrm{p}<.01$

\section{Results}

Table 1 shows that the mean of age for children was $(11.92 \pm 1.29)$ years old, whereas nearly half $(87.7 \%$ and $71.7 \%)$ of them their age was more than 10 years and in primary school respectively, $(66 \%)$ of them were male. More than half $(54.7 \%$ and $58.5 \%)$ of them their asthma started from 2 years and more, and they absent from school for more than 3 days last month due to asthma, respectively. Regarding parents education, nearly half $(54.7 \%)$ of fathers had basic education and (34.9\%) of mothers were illiterate. Table 2 reveals that most $(81.1 \%, 79.2 \%$ and $84.9 \%)$ of children their asthma triggers were having a cold and flu beside to exhaust fumes respectively. Additionally, more than two thirds $(69.8 \%$, $71.7 \%, 66 \%$ and $71.7 \%$ ) of them their triggers were cigarette smoke, running, being angry, feeling unhappy, and feathers from birds respectively.

Table (3) illustrates that nearly three quarters $(73.6 \%, 78.3 \%$, $76.4,73.6 \%$ and $70.8 \%$ ) of children pre intervention had unsatisfactory knowledge regarding general knowledge, symptoms, medications, triggers, and preventive measures. Also nearly half of them $(50.9 \%)$ had unsatisfactory knowledge regarding asthma management and majority (93.4\%) of them had unsatisfactory total knowledge regarding asthma. In addition it shows that. Also it shows that improvement in the knowledge of children post and follow up intervention phase regarding asthma with slightly decrease in follow up phase with highly statistically significant differences between pre, post and pre, follow up intervention phase $(\mathrm{p}>0.000)$.

Table 1: Number and Percent Distribution of Asthmatic Children According to Their Basic Information

\begin{tabular}{|c|c|c|}
\hline & & \\
\hline Parameter & $\mathrm{N}=106$ & $\%$ \\
\hline Mean of child age: & $11.92 \pm 1.29$ & \\
\hline 10 -ys & 13 & 12.3 \\
\hline$>10 y s$ & 93 & 87.7 \\
\hline Gender & & \\
\hline Male & 66 & 62.3 \\
\hline female & 40 & 37.7 \\
\hline Period of disease & & \\
\hline$\leq 2$ ys & 48 & 45.3 \\
\hline$>2 \mathrm{ys}$ & 58 & 54.7 \\
\hline Mean of disease period & $2.42 \pm 1.09$ & \\
\hline primary & 76 & 71.7 \\
\hline Preparatory & 30 & 28.3 \\
\hline School absenteeism for asthm & & \\
\hline$\leq 3$ days & 62 & 58.5 \\
\hline$>3$ days & 44 & 41.5 \\
\hline Father education & & \\
\hline basic & 58 & 54.7 \\
\hline Secondary and diploma & 26 & 24.5 \\
\hline High & 22 & 20.8 \\
\hline Mother education & & \\
\hline Illiterate & 37 & 34.9 \\
\hline basic & 22 & 20.8 \\
\hline Secondary and diploma & 27 & 25.5 \\
\hline High & 20 & 18.9 \\
\hline Mean of Father age & $36.62 \pm 5.15$ & \\
\hline Mean of mother age & $28.39 \pm 5.58$ & \\
\hline Family members with asthma & 28 & 26.4 \\
\hline
\end{tabular}


Table 2: Number and Percent Distribution of Asthma Triggers Experienced by Asthmatic Children

\begin{tabular}{|c|c|c|}
\hline Parameter & $\mathrm{N}=106$ & $\%$ \\
\hline Having a cold & 86 & 81.1 \\
\hline Cigarette smoke & 74 & 69.8 \\
\hline Running & 74 & 69.8 \\
\hline Being angry & 76 & 71.7 \\
\hline Pollen from trees & 8 & 7.5 \\
\hline Feeling alone & 28 & 26.4 \\
\hline Exhaust fumes & 90 & 84.9 \\
\hline Bicycle riding & 24 & 22.6 \\
\hline Stress at home & 14 & 13.2 \\
\hline Certain intensive odors & 64 & 60.4 \\
\hline Pollen from grass & 16 & 15.1 \\
\hline Feeling tense & 32 & 30.2 \\
\hline Climbing flights of stairs & 12 & 11.3 \\
\hline Depressed mood & 8 & 7.5 \\
\hline Smell of paint & 30 & 28.3 \\
\hline Sport activities & 32 & 30.2 \\
\hline Perfumes & 6 & 5.7 \\
\hline Arguments with people & 22 & 20.8 \\
\hline Flu & 84 & 79.2 \\
\hline Sinus problems & 4 & 3.8 \\
\hline Being excited & 20 & 18.9 \\
\hline Intense worries & 6 & 5.7 \\
\hline Feeling unhappy & 70 & 66 \\
\hline Animal hair & 10 & 9.4 \\
\hline Overexertion & 10 & 9.4 \\
\hline Viruses & 32 & 30.2 \\
\hline Feeling weak & 8 & 7.5 \\
\hline Feathers from birds & 76 & 71.7 \\
\hline Sprays & 12 & 11.3 \\
\hline Cats & 14 & 13.2 \\
\hline House dust & 16 & 15.1 \\
\hline
\end{tabular}

Table 3: Number and Percent Distribution of Knowledge Difference for Asthmatic Children Pre, Post and Follow up Intervention Phase

\begin{tabular}{|c|c|c|c|c|c|c|c|c|c|c|}
\hline \multirow{2}{*}{ Item } & \multicolumn{2}{|c|}{$\begin{array}{l}\text { Pre intervention } \\
\text { Total }=106\end{array}$} & \multicolumn{2}{|c|}{$\begin{array}{l}\text { Post intervention } \\
\text { Total }=106\end{array}$} & \multicolumn{2}{|c|}{$\begin{array}{l}\text { follow intervention } \\
\text { Total }=106\end{array}$} & \multirow{2}{*}{$\begin{array}{l}\mathrm{X}^{2} \\
\text { Pre-post }\end{array}$} & \multirow[t]{2}{*}{ P-value } & \multirow{2}{*}{\multicolumn{2}{|c|}{$\begin{array}{l}\mathrm{X}^{2} \quad \text { P-value } \\
\text { Pre-follow up }\end{array}$}} \\
\hline & No & $\%$ & No & $\%$ & No & $\%$ & & & & \\
\hline \multicolumn{11}{|c|}{ general knowledge: } \\
\hline Satisfactory & 28 & 26.4 & 84 & 79.2 & 63 & 59.4 & \multirow{3}{*}{59.36} & \multirow{3}{*}{$0.000 * *$} & & \\
\hline unsatisfactory & 78 & 73.6 & 22 & 20.8 & 43 & 40.6 & & & 23.58 & $0.000 * *$ \\
\hline Symptoms : & & & & & & & & & & \\
\hline Satisfactory & 23 & 21.7 & 90 & 84.9 & 77 & 72.6 & 85.06 & $0.000 * *$ & & \\
\hline Satisfactory & 25 & 23.6 & 86 & 81.1 & 71 & 67 & & & & \\
\hline unsatisfactory & 81 & 76.4 & 20 & 18.9 & 35 & 33 & 70.36 & $0.000 * *$ & 40.28 & $0.000 * *$ \\
\hline \multicolumn{11}{|l|}{ Triggers : } \\
\hline Satisfactory & 28 & 26.4 & 86 & 81.1 & 77 & 72.6 & \multirow{2}{*}{63.83} & \multirow{2}{*}{$0.000 * *$} & & \\
\hline unsatisfactory & 78 & 73.6 & 20 & 18.9 & 29 & 27.4 & & & 51.09 & $0.000 * *$ \\
\hline \multicolumn{11}{|c|}{ Preventive measures : } \\
\hline Satisfactory & 31 & 29.2 & 93 & 87.7 & 80 & 75.5 & \multirow{2}{*}{74.68} & \multirow{2}{*}{$0.000 * *$} & \multirow{2}{*}{45.40} & \multirow{2}{*}{$0.000 * *$} \\
\hline \multirow{2}{*}{\multicolumn{8}{|c|}{ Management }} & & & \\
\hline Satisfactory & 52 & 49.1 & 86 & 81.1 & 70 & 66 & \multirow{2}{*}{23.99} & \multirow{2}{*}{$0.000 * *$} & & \\
\hline unsatisfactory & 54 & 50.9 & 20 & 18.9 & 36 & 34 & & & 6.25 & $0.012 *$ \\
\hline \multicolumn{11}{|c|}{ Score of total knowledge } \\
\hline Satisfactory & 7 & 6.6 & 94 & 88.7 & 79 & 84.9 & \multirow{2}{*}{143.13} & \multirow{2}{*}{$0.000^{* *}$} & \multirow{2}{*}{101.42} & \multirow{2}{*}{$0.000 * *$} \\
\hline unsatisfactory & 99 & 93.4 & 12 & 11.3 & 27 & 15.1 & & & & \\
\hline
\end{tabular}

N.B. **highly significant * significant

Figure 1 shows that the total mean of knowledge regarding asthma pre intervention was $(11.07 \pm 2.71)$ which improved to $(21.84 \pm 3.25)$ and $(19.28 \pm 4.03)$ in post and follow up implementation phase respectively.

Tables (4) reveals that highly statistically significant difference in pre, post and follow up program implementation regarding to the mean of all aspects of self-efficacy of asthma management. Additionally, it shows improvement of total self-efficacy of asthma management whereas $(42.72 \pm 9.85), \quad(86.81 \pm 9.62)$ and $(81.55 \pm 10.88)$ were the mean score in pre, post and follow up program implementation.

Regarding asthma self-management table 5 illustrates that the nearly two thirds $(64.2 \%)$ of asthmatic children had inadequate management using preventive strategies. Nearly half of them had inadequate management regarding inhaler use. Additionally nearly three quarters $(79.2 \%)$ of them had inadequate management regarding differences between maintenance and rescue medications and, the majority $(90.6 \%)$ of them had inadequate management regarding use of peak flow meters. Regarding total management it reveals that nearly three quarters $(76.4 \%)$ of participants had inadequate asthma management before program implementation. Meanwhile it shows that improvement of asthma management after program implementation and follow up phase regarding all items of self-management with slightly decline in follow up phase with highly statistically significant difference in pre, post phase and pre follow up phase. 


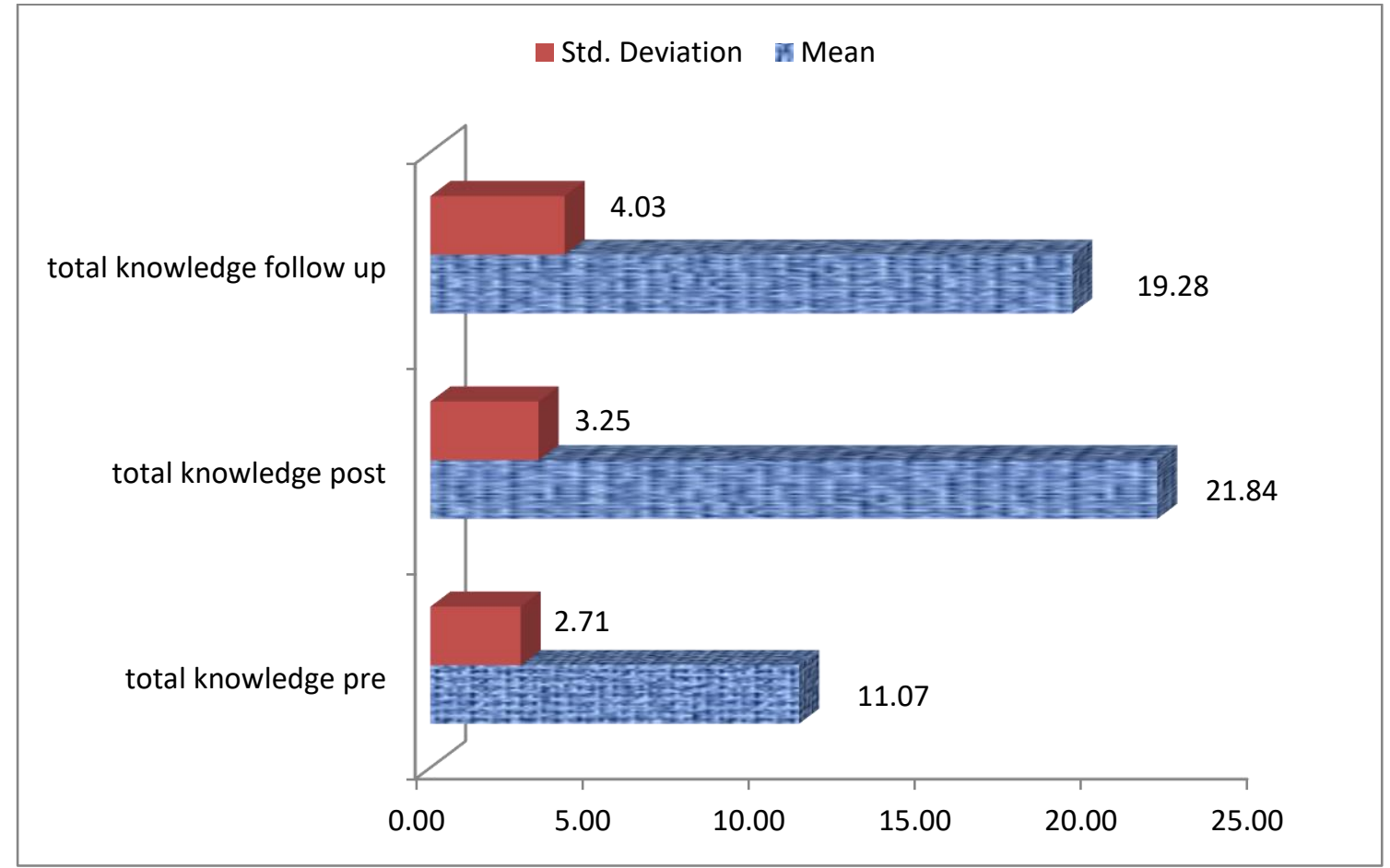

Fig. 1: Total Knowledge Mean and Standard Deviation Difference for Asthmatic Children Pre, Post and Follow up Intervention Phase.

Table 4: Mean Scores of Self-Efficacy of Self-Care Activities for Asthmatic Children Pre Post and Follow up Intervention Phase

\begin{tabular}{|c|c|c|c|c|c|c|c|c|}
\hline \multirow{2}{*}{ Self-Efficacy items } & \multirow{2}{*}{$\begin{array}{l}\text { pre } \\
\text { mean }\end{array}$} & \multirow[b]{2}{*}{ SD } & \multirow{2}{*}{$\begin{array}{l}\text { post } \\
\text { mean }\end{array}$} & \multirow[b]{2}{*}{ SD } & \multicolumn{2}{|c|}{ Follow up } & \multicolumn{2}{|l|}{ Repeated-measured } \\
\hline & & & & & mean & SD & ANOVA & SIGN \\
\hline Basic information/feelings about asthma & 9.78 & 2.35 & 17.94 & 1.30 & 16.45 & 1.89 & 639.39 & $0.000 * *$ \\
\hline Recognizing and managing asthma symptoms & 20.39 & 4.20 & 42.55 & 7.27 & 39.54 & 9.65 & 532.33 & $0.000 * *$ \\
\hline Finding and controlling asthma triggers & 1.79 & 0.75 & 3.41 & 0.74 & 3.10 & 0.77 & 155.55 & $0.000 * *$ \\
\hline Keeping your battery charged: How to get enough exercise & 2.99 & 1.39 & 6.60 & 1.43 & 6.67 & 0.88 & 306.21 & $0.000 * *$ \\
\hline Doing well in school & 1.52 & 0.77 & 3.11 & 0.69 & 3.04 & 0.62 & 217.57 & $0.000 * *$ \\
\hline
\end{tabular}

N.B. **highly significant * significant

Table 5: Number and Percent Distribution of Asthma Self-Management Difference for Asthmatic Children Pre, Post and Follow up Intervention Phase

\begin{tabular}{|c|c|c|c|c|c|c|c|c|c|c|}
\hline \multirow[t]{2}{*}{ Item } & \multicolumn{2}{|c|}{$\begin{array}{l}\text { Pre intervention } \\
\text { Total }=106\end{array}$} & \multicolumn{2}{|c|}{ Post intervention Total $=106$} & \multicolumn{2}{|c|}{ follow intervention Total $=106$} & \multirow{2}{*}{$\begin{array}{l}\mathrm{X}^{2} \\
\text { Pre-post }\end{array}$} & \multirow[t]{2}{*}{ P-value } & $X^{2}$ & P-value \\
\hline & No & $\%$ & No & $\%$ & No & $\%$ & & & \multicolumn{2}{|c|}{ Pre-follow up } \\
\hline \multicolumn{11}{|c|}{ Management using preventive strategies: } \\
\hline Adequate & 38 & 35.8 & 92 & 86.8 & 81 & 76.4 & \multirow{3}{*}{57.99} & \multirow{3}{*}{$0.000 * *$} & & \\
\hline Inadequate & 68 & 64.2 & 14 & 13.2 & 25 & 23.6 & & & 35.42 & $0.000 * *$ \\
\hline \multicolumn{9}{|l|}{ Inhaler use : } & & \\
\hline Adequate & 51 & 48.1 & 93 & 87.7 & 77 & 72.6 & \multirow{2}{*}{38.19} & \multirow{2}{*}{$0.000 * *$} & & \\
\hline Inadequate & 55 & 51.9 & 13 & 12.3 & 29 & 27.4 & & & 13.32 & $0.000 * *$ \\
\hline \multicolumn{11}{|c|}{ Differences between maintenance and rescue medications } \\
\hline Adequate & 22 & 20.8 & 89 & 84 & 76 & 71.7 & \multirow{2}{*}{84.88} & \multirow{2}{*}{$0.000 * *$} & & \\
\hline Inadequate & 84 & 79.2 & 17 & 16 & 30 & 28.3 & & & 55.33 & $0.000 * *$ \\
\hline \multicolumn{11}{|c|}{ Use of peak flow meters : } \\
\hline Adequate & 10 & 9.4 & 80 & 75.5 & 67 & 63.2 & \multirow{2}{*}{94.60} & \multirow{2}{*}{$0.000 * *$} & & \\
\hline Inadequate & 96 & 90.6 & 26 & 24.5 & 39 & 36.8 & & & 66.26 & $0.000 * *$ \\
\hline \multicolumn{11}{|c|}{ Total asthma self-management: } \\
\hline Adequate & 25 & 23.6 & 98 & 92.5 & 84 & 79.2 & \multirow{2}{*}{103.20} & \multirow{2}{*}{$0.000 * *$} & \multirow{2}{*}{65.73} & \multirow{2}{*}{$0.000 * *$} \\
\hline Inadequate & 81 & 76.4 & 8 & 7.5 & 22 & 20.8 & & & & \\
\hline
\end{tabular}

N.B. **highly significant * significant

Figure 2 explains that that the total mean of self-management regarding asthma pre intervention was $(38.00 \pm 16.36)$ which improved to $(81.36 \pm 11.95)$ and $(75.05 \pm 14.95)$ in post and follow up implementation phase respectively.

Table 6 reveals that nearly three quarters $(70.8 \%)$ of children with asthma had low adherence to asthma medications before implementation of the program which improved after and follow up phase. Whereas $(90.6 \%)$ and $(78 \%)$ of them was adhere to asthma medications respectively, with highly statistically significant difference $(\mathrm{p}>000)$.
Regarding inhaler use table 7 shows that nearly one quarter $(27.4 \%)$ of children were use inhaler correctly before implementation of the program while the majority $(86.8 \%$ and $77.4 \%)$ of them were use it correctly after and follow up program implementation respectively with highly statistically significant difference $(\mathrm{p}>$ 000). 


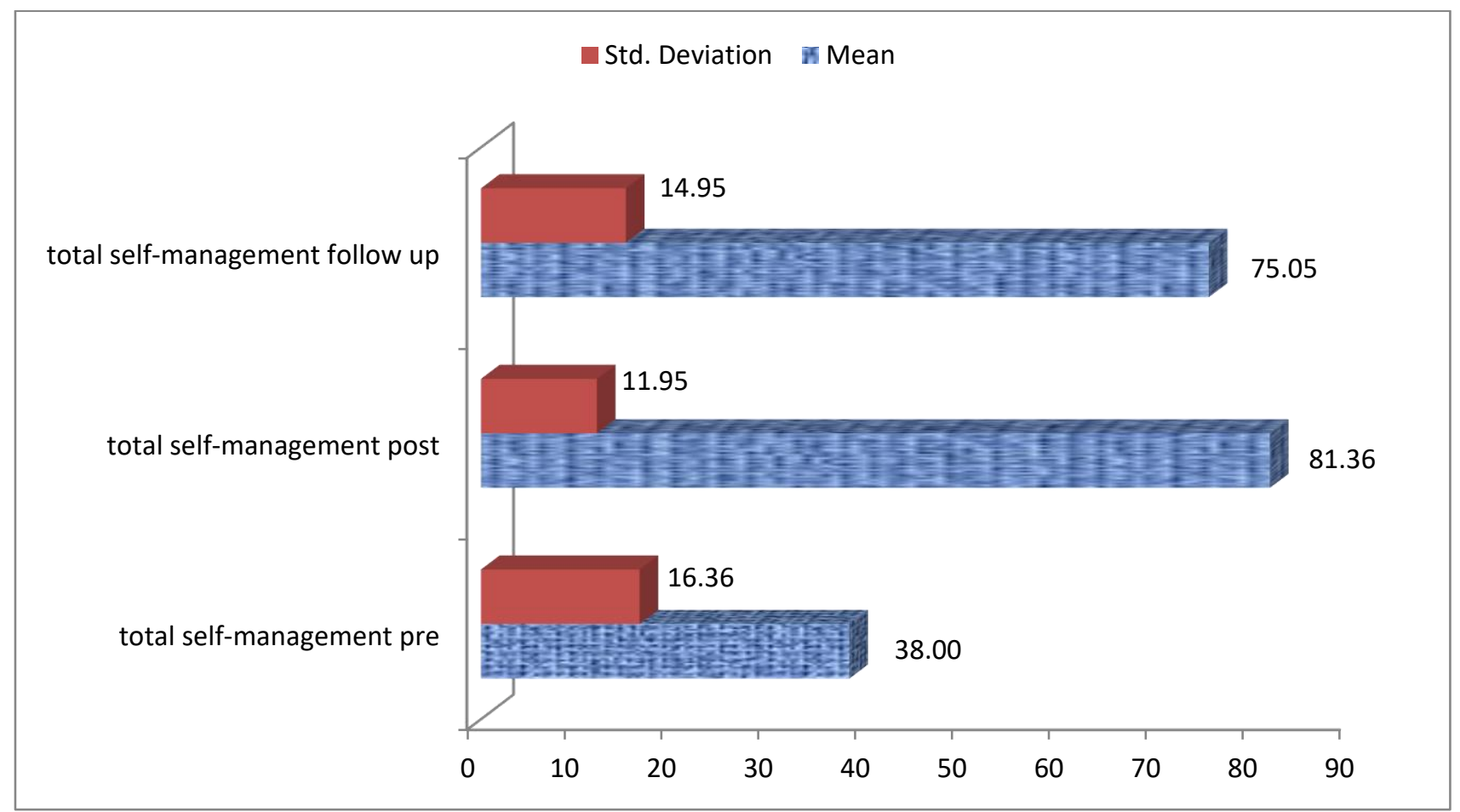

Fig. 2: Total Self-Management Mean and Standard Deviation Difference for Asthmatic Children Pre, Post and Follow up Intervention Phase.

Table 6: Number and Percent Distribution Regarding Scores of Adherence to Medications for Asthmatic Children Pre, Post and Follow up Intervention Phase

\begin{tabular}{|c|c|c|c|c|c|c|c|c|}
\hline \multirow{2}{*}{ Items } & \multicolumn{2}{|l|}{ pre } & \multicolumn{2}{|c|}{ post } & \multicolumn{2}{|c|}{ Follow up } & \multirow{2}{*}{ Repeated measure ANOVA } & \multirow{2}{*}{$P$ value } \\
\hline & No & $\%$ & No & $\%$ & No & $\%$ & & \\
\hline \multicolumn{9}{|c|}{ adherence to medications } \\
\hline High score & 31 & 29.2 & 96 & 90.6 & 78 & 73.6 & & \\
\hline Low score & 75 & 70.8 & 10 & 9.4 & 28 & 26.4 & 283.95 & $0.000 * *$ \\
\hline Mean Score & \multicolumn{2}{|c|}{$3.57 \pm 1.37$} & \multicolumn{2}{|c|}{$6.22 \pm 0.87$} & \multicolumn{2}{|c|}{$5.60 \pm 1.16$} & & \\
\hline
\end{tabular}

N.B. **highly significant $*$ significant

Table 7: Number and Percent Distribution Regarding Scores of Inhaler Use for Asthmatic Children Pre, Post and Follow up Intervention Phase

\begin{tabular}{|c|c|c|c|c|c|c|c|c|}
\hline \multirow[b]{2}{*}{ Items } & \multicolumn{2}{|c|}{ pre } & \multicolumn{2}{|c|}{ post } & \multicolumn{2}{|c|}{ Follow up } & \multirow[b]{2}{*}{ Repeated measure ANOVA } & \multirow[b]{2}{*}{$P$ value } \\
\hline & No & $\%$ & No & $\%$ & No & $\%$ & & \\
\hline \multicolumn{9}{|l|}{ Inhaler Use } \\
\hline High score & 29 & 27.4 & 92 & 86.8 & 82 & 77.4 & & \\
\hline Low score & 77 & 72.6 & 14 & 13.2 & 24 & 22.6 & 264.25 & $0.000^{* *}$ \\
\hline Mean Score & \multicolumn{2}{|c|}{$4.33 \pm 1.39$} & \multicolumn{2}{|c|}{$8.18 \pm 1.50$} & \multicolumn{2}{|c|}{$7.37 \pm 1.72$} & & \\
\hline
\end{tabular}

N.B. **highly significant * significant

\section{Discussion}

Developing self-care skills related to the chronic diseases forms a basis for nursing related to the care of children with asthma. Children with asthma need supportive and educational nursing approaches and guidance. Clients education in asthma selfmanagement has developed as a nursing intervention to help patients to manage and recognize asthma, and hopefully to become active, self-efficacious contributors in their asthma care (AlAtawi, 2017). By relevance, self-care pattern is a significant training pattern which is based on the person abilities and needs. For example, Orem's self-care model is a self-care pattern which is a suitable clinical guideline to plan for and implement self-care principles and might be applied as a conceptual framework to conduct self-care programs (Hemati et al, 2015).

So this intervention study was conducted to examine the effect of asthma education program on asthma self-care activities among children Based on Orem's Self-Care model in Zagazig city.

Regarding baseline characteristics our findings revealed that more than half of participants their asthma started from 2 years and more, and they absent from school for more than 3 days last month due to asthma which could be due to climate change at the period of data collection. This finding was similar to Guarnaccia et al (2017) who found that twenty percent of children missed at least one day of school because of asthma.

In the current study, the most asthma triggers among children were cold and flu, exhaust fumes, cigarette smoke, running, being angry, feeling unhappy, and feathers from birds that is in agreement with Stridsman et al (2017)who described asthma triggers by to be poor air quality, poorly cleaned environment, allergens, strong fragrance, rebuilding projects, physical education and stress. It was obvious that one of the causes of failure to control asthma can be related to lack of knowledge of triggers and the failure to avoid them. So; accurate identification of asthma triggers often is a requirement for adequate asthma management.

In our study level of knowledge were improved significantly post intervention with slightly decrease in follow up phase which agrees with the study of by Coelho et al (2017) which, confirmed that majority of the adolescents had previously unsatisfactory knowledge about asthma. The relief and maintenance treatment were the most unknown issues in their sample. Additionally, observed was an extreme presence of beliefs in popular myths that interfered with disease understanding. The health education used through intervention promoted a great improvement in adolescents' knowledge of asthma. Furthermore, a study done by Elliot (2014) demonstrated that student pharmacist delivered asthma education was succeeding in enhancing asthma knowledge in children. However, knowledge of asthma concept, causes, symptoms, 
triggers, and medication use improved significantly in the child cohort after participation in the education program.

Improvement of knowledge among participants in this study can be justified due to patient education in asthma self-management has emerged as a nursing intervention to help patients to manage and understand asthma, and hopefully to become active, selfefficacious participants in their asthma care.

The current study showed that the asthma education program improved all aspects of self-efficacy of asthma management after intervention and follow up program implementation. It agrees with the study of Guner and Celebioglu (2015) which found that The training and information provided to children with asthma during home-visits enhanced self-efficacy levels and consequently educated the children about appropriate treatment and monitoring of their asthma, helped avoid exposure to causes that trigger asthma symptoms, and eventually improved the patients' ability to manage their asthma daily. Additionally it consistent Hemati et al (2015) revealed that the training classes attended by asthmatic children based on Orem's self-care model caused advancement of self-esteem in the adolescents with asthma, whereas the selfesteem mean score in study group after the training program was significantly different from that before the training.

In the current study there was a significant improvement of asthma management after program implementation and follow up phase with slightly decline in follow up phase. This finding may be explained by using self-car model assuming children responsibility for the treatment and management of their illness and gains more independence for them especially children with asthma who require supportive and educational nursing approaches and guidance. This finding is in agreement with previous school-based asthma interventions study done by Bruzzese et al (2011)who proved that asthma self-management of adolescents is effective in enhancing asthma self-management and decreasing asthma morbidity and emergency health care use in low-income urban minority adolescents. Similarly Altay and Çavus, og lu (2013) stated that the self-care skills had improved in the intervention group at the last visit for medication, PEF meter, maintaining a daily follow-up chart, implementation of asthma action plan, and protection against triggers. Their findings revealed that education and consultation program as well as intermittent home follow-up according to Orem's self-care model effectively facilitated an enhancement in the respective self-care skills of adolescents with asthma. Additionally Ekim and Ocakci (2016) stated that the discharge planning education, home visit, and telephone counseling given to the experimental group were useful in improving asthma management. The unscheduled outpatient clinic visits and numbers of admissions to emergency departments were significantly decreased for the experimental group. The asthma management selfefficacy awareness level of mothers in study group following intervention was significantly higher than that of mothers of the control group.

In this study, the significant effect of asthma education on adherence to asthma medications whereas three quarters of children with asthma had low adherence to asthma medications before implementation of the program which improved after and follow up phase. This result is consistent with the findings of a study conducted by Foster et al (2014) who observe the provision of inhaler reminders and adherence feedback in primary care, recommends that reminders offer a simple, practicable, and greatly effective strategy for promoting the adherence of general practice clients with asthma. This influential combination of reminder and feedback offer an effective strategy for improving adherence. Furthermore, Elbanna et al (2017) added that patient education can be a crucial element of the improvement of adherence and their findings proved that highly significant improvement in adherence to action plan with asthma educational intervention.

The current study revealed that educational program based on Orem's self-care model successfully improve the performance of inhaler use among children. Our participants showed better outcomes possibly because they motivated to correctly use of inhaler. So, proper education for asthmatic children can acquire the neces- sary knowledge, skills and confidence as well as engaging in proper behavior to control or reduce the effect of asthma, and collaborate with nurse in order to be active partners in the treatment. This finding agrees with Ranaut et al (2013) and Türkeli et al (2016)studies which proved that repetitive demonstrations regarding use of MDI of appropriate technique is an effective method for improving performance regarding the use of the inhaler with or without spacer and asthma control in children. Additionally Kalaldeh et al (2016) added that Nurse-driven inhaler education enhanced inhaler proficiency scores and adherence while before implementation participants showed insufficient knowledge of general inhaler use, with difficulty use and complications from using the inhalers.

\section{Conclusion: it was concluded that}

The total mean of knowledge regarding asthma was improved in post and follow up implementation phase. It reveals that highly statistically significant difference in pre, post and follows up program implementation regarding to the mean of all aspects of selfefficacy of asthma management and asthma management. Additionally, it shows improvement of total self-efficacy and asthma management in pre, post and follows up program implementation. Majority of children with asthma had low adherence to asthma medications before implementation of the program which improved after and follow up phase, with highly statistically significant difference $(p>000)$. Regarding inhaler use the majority of asthmatic children were use it correctly after and follow up program implementation with highly statistically significant difference $(p>000)$. The results of the study indicated that implementation of educational package on children with asthma based on Orem's self-care model improve all aspects of self-management.

\section{Recommendations}

- It is recommended to implement this program based on Orem's self-care model in many settings to support its effectiveness.

- It is suggested to test the effectiveness of the developed program in a randomized clinical trial to confirm the findings.

- It is important to continuously monitor and evaluate the self-care of children and adolescents with asthma through follow-up visits at outpatient clinics and home. We believe it may be possible to greatly reduce inadequate self-care with the counseling, support, and training provided during follow up visits.

\section{Conflict of interest}

- $\quad$ The author(s) declare that they have no competing interests. All listed authors meet the authorship criteria, and all authors are in agreement with the content of the manuscript.

- The author(s) declare that they have no competing interests. All listed authors meet the authorship criteria, and all authors are in agreement with the content of the manuscript.

- The authors declare that they had no conflict of interest. All listed authors meet the authorship criteria, and all authors are in agreement with content of the manuscript.

\section{References}

[1] Al-Atawi, A. (2017): The Effectiveness of Asthma Education Approaches for Children: Group versus Individual Education. Biomedical Journal of Scientific \& Technical Research 1(3)- 2017, https://doi.org/10.26717/BJSTR.2017.01.000306.

[2] Al-Kalaldeh, M., El-Rahman, M. A., \& El-Ata, A. (2016). Effectiveness of Nurse-Driven Inhaler Education on Inhaler Proficiency and Compliance among Obstructive Lung Disease Patients: A Qua- 
si-Experimental Study. Canadian Journal of Nursing Research, 48(2), 48-55. https://doi.org/10.1177/0844562116676119.

[3] AlMotlaq, M. \&Sellick, K. (2011).Development and Validation of an Asthma Knowledge Test for Children 8-10 Years of Age. Child Care Health and Development, 37(1), 123 https://doi.org/10.1111/j.1365-2214.2010.01133.x.

[4] Alreshidi, N. M. (2015). The impact of a school-based, nursedelivered asthma health education programme on quality of life, knowledge and attitudes of Saudi children with asthma (Doctoral dissertation, University of Salford).

[5] Altay, N., andÇavuşoğlu, H. (2013).Using Orem's self-care model for asthmatic adolescents. Journal for Specialists in Pediatric Nursing, 18(3), 233-242. https://doi.org/10.1111/jspn.12032.

[6] Borji M, Otaghi M, Kazembeigi S. The Impact of Orem's Self-Care Model on the Quality of Life in Patients with Type II Diabetes. Biomed Pharmacol J 2017; 10(1). Available from: http://biomedpharmajournal.org/?p=13576

[7] Bruzzese, J. M., Sheares, B. J., Vincent, E. J., Du, Y., Sadeghi, H., Levison, M. J. \& Evans, D. (2011). Effects of a school-based intervention for urban adolescents with asthma: a controlled trial. American journal of respiratory and critical care medicine, 183(8), 9981006. https://doi.org/10.1164/rccm.201003-04290C.

[8] Coelho, A. C. C., de Souza-Machado, C., de Oliveira, T. S., do Santos, T. N. N., Cruz, Á. A., and Souza-Machado, A. (2017). Curricular intervention increases adolescents' knowledge about asthma: a randomized trial. Jornal de Pediatria. https://doi.org/10.1016/j.jped.2017.06.014.

[9] Dima, A. L., de Bruin, M., \& Van Ganse, E. (2016).Mapping the asthma care process: implications for research and practice. The Journal of Allergy and Clinical Immunology: In Practice, 4(5), 868-876. https://doi.org/10.1016/j.jaip.2016.04.020.

[10] Ekim, A., \&Ocakci, A. F. (2016).Efficacy of a Transition TheoryBased Discharge Planning Program for Childhood Asthma Management. International journal of nursing knowledge, 27(2), 70-78. https://doi.org/10.1111/2047-3095.12077.

[11] Elbanna, R. M., Sileem, A. E., Bahgat, S. M., \&Ibrahem, G. A. (2017).Effect of bronchial asthma education program on asthma control among adults at Mansoura district.Egyptian Journal of Chest Diseases and Tuberculosis https://doi.org/10.1016/j.ejcdt.2017.03.001.

[12] Elliott, J. P., Marcotullio, N., Skoner, D. P., Lunney, P., \& Gentile, D. A. (2014).Impact of Student Pharmacist-Delivered Asthma Education on Child and Caregiver Knowledge.American Journal of

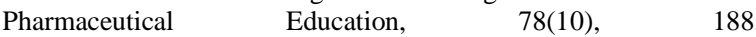
https://doi.org/10.5688/ajpe7810188.

[13] El-Mashad GM, Mahmoud AA, Abdel Hafez AA.The prevalence of bronchial asthma among primary school children in Menoufiya Governorate (El-Bagour Center).Menoufia Med J [serial online] 2016 [cited 2017 Oct 2];29:89-94. Available from: http://www.mmj.eg.net/text.asp?2016/29/1/89/178992

[14] Foster, J. M., Usherwood, T., Smith, L., Sawyer, S. M., Xuan, W., Rand, C. S., \&Reddel, H. K. (2014). Inhaler reminders improve adherence with controller treatment in primary care patients with asthma. Journal of Allergy and Clinical Immunology, 134(6), 12601268. https://doi.org/10.1016/j.jaci.2014.05.041.

[15] Gajanan, G., Padbidri, V. S., \&Chaudhury, A. (2016). Assessmen of Knowledge and Attitude of Parents towards the Allergy and Bronchial Asthma in Their Children. International Journal of Medicine and Public Health, 6(3). https://doi.org/10.5530/ijmedph.2016.3.5.

[16] Georgy, V., Fahim, H. I., El Gaafary, M., \& Walters, S. (2006). Prevalence and socioeconomic associations of asthma and allergic rhinitis in northern Africa. European Respiratory Journal, 28(4), 756-762. https://doi.org/10.1183/09031936.06.00089005.

[17] Guarnaccia, S., Pecorelli, G., Bianchi, M., Cartabia, M., Casadei, G., Pluda, A., \&Bonati, M. (2017). IOEASMA: an integrated clini$\mathrm{cal}$ and educational pathway for managing asthma in children and adolescents. Italian journal of pediatrics, 43(1), 58 https://doi.org/10.1186/s13052-017-0374-8.

[18] Guner U.C. \&Celebioglu A. (2015) Impact of symptom management training among asthmatic children and adolescents on selfefficacy and disease course, Journal of Asthma, 52:8, 858-865, https://doi.org/10.3109/02770903.2015.1010732.

[19] Hemati, Z., Mosaviasl, F. S., Abasi, S., Ghazavi, Z., \&Kiani, D. (2015). Effect of Orem's Self-Care Model on Self-Esteem of Adolescents with Asthma Referred to an Asthma and Allergy Clinic in Isfahan. Tanaffos, 14(4), 232-237

[20] Janssens, T., \& Ritz, T. (2013). Perceived triggers of asthma: key to symptom perception and management. Clinical \& Experimental Allergy, 43(9), 1000-1008. https://doi.org/10.1111/cea.12138.
[21] Kaur, S., Behera, D., Gupta, D., \&Verma, S. K. (2009). Evaluation of a'Supportive Educative Intervention'on self-care inpatients with bronchial asthma. Nursing and Midwifery Research Journal, 5(2).

[22] Magwentshu, Z. T. (2010). Knowledge and practice on the use of metered dose inhalers by asthmatic patients seen at a Private General Practice in the Vhembe District, Limpopo Province (Doctoral dissertation, University of Limpopo (Medunsa Campus)).

[23] Manchana, V., \&Mahal, R. K. (2014).Impact of Asthma Educational Intervention on Self-Care Management of Bronchial Asthma among Adult Asthmatics. Open Journal of Nursing, 4(11), 743 https://doi.org/10.4236/ojn.2014.411080.

[24] Mancuso, C. A., Sayles, W., \&Allegrante, J. P. (2009).Development and testing of the asthma self-management questionnaire. Annals of Allergy, Asthma \& Immunology, 102(4), 294-302. https://doi.org/10.1016/S1081-1206(10)60334-1.

[25] McCorkle, L. S. (2005). A study of the relationships of self-efficacy of self-management of asthma and asthma self-management knowledge (Doctoral dissertation, Texas A\&M University).

[26] Morisky, D. E., Ang, A., Krousel-Wood, M., \& Ward, H. J. (2008).Predictive validity of a medication adherence measure in an outpatient setting. Journal of Clinical Hypertension, 10(5), 348-354 https://doi.org/10.1111/j.1751-7176.2008.07572.x.

[27] Nejad, M. M., Nejad, G. S., Tavakol, H., \&Cheraghi, M. (2017).The effect of the training program on the quality of life in patients with asthma based on the Precede model in Ahvaz, Iran. PostepyDermatologii $i \quad$ Alergologii, 34(3), 216. https://doi.org/10.5114/ada.2017.67844.

[28] Rabie, T., \&Klopper, H. C. (2015).Guidelines to facilitate self-care among older persons in South Africa. healthsagesondheid, 20(1), 33-44. https://doi.org/10.1016/j.hsag.2015.02.005.

[29] Ranaut V., Kaur S., kaur S., Singh M. (2013): Effect of intervention on the use of Metered Dose Inhaler amongst the children suffering with asthma and their caregivers, IOSR Journal of Nursing and Health Science Volume 3, Issue 1 Ver. I, (Nov. - Dec. 2013), PP 23-30 www.iosrjournals.org

[30] Ritz, T., Steptoe, A., Bobb, C., Harris, A. H. S., \& Edwards, M. (2006). The asthma trigger inventory: Validation of a questionnaire for perceived triggers of asthma. Psychosomatic Medicine, 68(6), 956-965. https://doi.org/10.1097/01.psy.0000248898.59557.74.

[31] Stridsman, C., Dahlberg, E., Zandrén, K., \&Hedman, L. (2017). Asthma in adolescence affects daily life and school attendanceTwo cross-sectional population-based studies 10 years apart. Nursing Open. https://doi.org/10.1002/nop2.77.

[32] Türkeli, A., Yılmaz, Ö, \&Yüksel, H. (2016). Metered dose inhalerspacer use education effects on achieve asthma control in children. Tuberkulozvetoraks, 64(2), 105-111. https://doi.org/10.5578/tt.9142.

[33] Urrutia-Pereira, M., To, T., Cruz, Á. A., \&Solé, D. (2017). The school as a health promoter for children with asthma: The purpose of an education programme. Allergologiaetimmunopathologia, 45(1), 93-98.

[34] Zedan, M., Settin, A., Farag, M., Ezz-Elregal, M., Osman, E., \&Fouda, A. (2009).Prevalence of bronchial asthma among Egyptian school children. Egypt J Bronchol, 3(2), 124-130. 